\title{
Écologie, systèmes de culture et utilisations alimentaires des ignames en Afrique tropicale : synthèse bibliographique
}

\author{
Fiacre Hermann Adifon ${ }^{1,4,}{ }^{*}$, Ibouraïma Yabi $^{2}$, Pierre Vissoh ${ }^{3}$, Ibouraïman Balogoun ${ }^{1}$, Joseph Dossou ${ }^{4}$ \\ et Aliou Saïdou ${ }^{1}$ \\ ${ }^{1}$ Unité de Recherche sur la Gestion Intégrée des Sols et des Cultures, Laboratoire des Sciences du Sol, École des Sciences et Techniques \\ de Production Végétale, Faculté des Sciences Agronomiques, Université d'Abomey-Calavi, 01 BP 526, RP Cotonou, Bénin \\ ${ }^{2}$ Laboratoire Pierre PAGNEY «Climat, Eau, Ecosystème et Développement», Université d'Abomey-Calavi, Faculté des Lettres, \\ Arts et Sciences Humaines, Département de Géographie et Aménagement du Territoire, 01 BP 526, RP Cotonou, Bénin \\ ${ }^{3}$ Département d'Économie Rurale, de Sociologie et de Vulgarisation, Faculté des Sciences Agronomiques, Université d'Abomey-Calavi, \\ 01 BP 526, RP Cotonou, Bénin \\ ${ }^{4}$ Laboratoire de Bioingenierie des Procédés Alimentaires (LABIOPA), Faculté des Sciences Agronomiques (FSA), \\ Université d'Abomey-Calavi, 01 BP 526, RP Cotonou, Bénin
}

\begin{abstract}
Résumé - Cette revue de littérature couvre la botanique, la domestication, l'écologie, les systèmes de culture, la transformation ainsi que les contraintes et perspectives pour une production durable des ignames en Afrique tropicale. L'igname est un taxon d'espèces essentiellement tropicales qui nécessitent des températures élevées. Ainsi, la germination est optimale entre 25 et $30^{\circ} \mathrm{C}$, alors que des températures inférieures à $15^{\circ} \mathrm{C}$ ou supérieures à $35^{\circ} \mathrm{C}$ la retardent. La culture de $1^{\prime}$ igname se pratique avec succès dans des zones où la pluviométrie varie entre 1000 et $1800 \mathrm{~mm}$; toutefois, il est possible de cultiver l'igname avec une pluviométrie de $600 \mathrm{~mm}$ mais le rendement reste faible. L'igname, pour la croissance végétative et une bonne tubérisation, préfère des sols limono-sableux ou sablo limoneux, ayant une conductivité hydraulique de $15 \mathrm{~cm} / \mathrm{h}$, une densité apparente comprise entre 1,1 et $1,6 \mathrm{~g} . \mathrm{cm}^{-3}$ et surtout légers, profonds $(>0,6 \mathrm{~m})$, bien drainés, riches en matière organique, en azote, en potasse, en magnésium et en calcium; un $\mathrm{pH}$ compris entre 5 et 7 est aussi propice à une bonne culture d'igname. Au-delà des paramètres édaphiques et des facteurs climatiques, les pratiques culturales, notamment le type de cultivar, la densité de plantation, la date de plantation, les adventices, les maladies et ravageurs, sans occulter l'histoire des parcelles et les pratiques paysannes de gestion du sol, ont un effet sur la productivité des ignames. Les facteurs déterminant le choix des variétés d'igname cultivées par les producteurs sont principalement: la qualité culinaire des tubercules, la productivité, la valeur commerciale, la facilité de multiplication, la qualité des cossettes, la précocité de tubérisation, la conservation, la facilité de culture, le rôle dans l'alimentation et l'importance pour les cérémonies rituelles.
\end{abstract}

Mots clés : sécurité alimentaire / tubercules / déforestation / consommation / Bénin

\begin{abstract}
Yam: ecology, cropping systems and food uses in tropical Africa. A literature review. This paper presents a literature review about botany, ecology, cropping systems, processing, constraints and prospects of sustainable yam production in tropical regions of Africa. Yam is a taxon of mainly tropical species requiring high temperatures. Germination is optimal between 25 and $30^{\circ} \mathrm{C}$, whereas temperatures below $15^{\circ} \mathrm{C}$ or above $35^{\circ} \mathrm{C}$ delay it. Yam is successfully cultivated in areas with rainfall ranging from 1000 to $1800 \mathrm{~mm}$; however, it is possible to cultivate yam with a rainfall of only $600 \mathrm{~mm}$, but yield remains low. To reach vegetative growth and good tuber formation, yam prefers sandy-loamy or loamy soils, with hydraulic conductivity of $15 \mathrm{~cm} / \mathrm{h}$, apparent soil density between 1.1 and $1.6 \mathrm{~g} . \mathrm{cm}^{-3}$ and light and deep soils $(>0.6 \mathrm{~m})$, well drained, rich in organic matter, nitrogen, potash, magnesium and calcium. A soil $\mathrm{pH}$ from 5 to 7 is suitable for a good yam production. Beyond the edaphic and climatic factors, cultivation practices, including cultivar, plantation density, date of planting, management of weeds, diseases and pests, cropping
\end{abstract}

\footnotetext{
*Auteur de correspondance : adifonf@yahoo.fr
} 
history of plots and farmers' soil management practices, affect yam productivity. Farmers base the choice of yam varieties mainly on culinary quality of tubers, productivity, commercial value, propagation, quality of chips, tuber formation precocity, conservation, facility of culture, roles as food and for ritual ceremonies.

Keywords: food security / tuber / deforestation / consumption / Benin

\section{Introduction}

Dans les régions tropicales, les plantes à racines et tubercules (manioc, patate douce, pomme de terre et igname) constituent des cultures alimentaires importantes. Leur volume total de production était d'environ 866 millions de tonnes en 2017 et la valeur agrégée de ces plantes à racines et tubercules dépasse celle de toutes les autres cultures vivrières en Afrique tropicale et y est largement supérieure à la valeur totale des cultures céréalières (FAOSTAT, 2019).

Parmi ces plantes à racines et tubercules, l'igname (Dioscorea spp.), avec une production de 71 millions de tonnes en 2017, constitue la base de l'alimentation de plus de 500 millions de personnes dans certains pays tropicaux d'Afrique, des Caraïbes, d'Océanie et d'Amérique latine (Onyeka et al., 2006; FAOSTAT, 2019). Cette production se concentre principalement (plus de $93 \%$ de la production mondiale) dans les savanes entourant le Golfe de Guinée, formant une «ceinture de l'igname»; elle y joue un rôle très important dans la sécurité alimentaire d'au moins 60 millions de personnes (Adeniji et al., 2012; Cornet, 2015; Sanginga et Mbabu, 2015). Le Nigeria est, de loin, le premier pays producteur d'igname au monde, avec plus de 48 millions de tonnes, soit plus de $70 \%$ de la production mondiale, évaluée à $73 \mathrm{Mt}$ en 2017 (FAOSTAT, 2019).

La production mondiale d'igname a presque triplé au cours des trois dernières décennies, en particulier au Nigeria, au Bénin et au Ghana; le potentiel de l'igname laisse à penser qu'elle pourrait être, dans un proche avenir, un recours pour répondre aux besoins alimentaires grandissants des populations (Asiedu et Sartie, 2010). En Afrique, bien que la zone de production d'igname se concentre dans les pays côtiers du Golfe de Guinée (Vernier et Dansi, 2006; Olufemi et al., 2016), sa culture s'étend ces dernières décennies vers les zones tropicales humides d'Afrique centrale (Cameroun, République Centre-africaine, Tchad, Gabon) ainsi qu'à Madagascar. Le Brésil, la Colombie, la Jamaïque, Haïti, la Dominique, la Papouasie-Nouvelle Guinée et Sao-Tomé sont aussi des pays producteurs d'igname (FAOSTAT, 2019).

$\mathrm{Si}$ la majorité des espèces d'ignames se rencontrent dans les zones intertropicales (entre $20^{\circ} \mathrm{N}$ et $20^{\circ} \mathrm{S}$ ), l'igname se cultive également en zone tempérée: Argentine, France et Japon (Cornet, 2015; FAOSTAT, 2019). Au Bénin, la production moyenne annuelle d'igname sur les dix dernières campagnes est de 2730000 tonnes (DSA, 2017). Au cours de la campagne agricole 2016-2017, la production béninoise a été de 3041245 tonnes, soit $5 \%$ de la production mondiale (DSA et MAEP, 2017), ce qui classe le Bénin au quatrième rang des pays producteurs d'igname après le Nigeria (70\% de la production mondiale), la Côte d'Ivoire (9\%) et le Ghana (7\%). L'igname est donc considérée comme l'un des produits stratégiques pour la sécurité alimentaire du Bénin, où les départements favorables à sa production sont les Collines, le
Borgou, la Donga, l'Atacora, l'Alibori, le Zou et le Plateau (Fig. 1).

L'igname joue un rôle important dans les rituels tels que les mariages et les fêtes annuelles, au point que Baco et al. (2007) déclarent que l'igname a une signification qui va bien au-delà de celle d'autres cultures en milieu tropical. Les agriculteurs cultivent l'igname pour leur autoconsommation et génèrent aussi des revenus en commercialisant les surplus (Maliki et al., 2012). L'igname est donc devenue une culture de rente qui alimente les marchés urbains. Selon Sodjinou et al. (2009), l'igname est beaucoup moins sensible aux fluctuations des prix que les céréales lorsque des crises surviennent sur les marchés internationaux. La culture de l'igname contribue donc à améliorer la stabilité du système alimentaire et accroît la prévisibilité des revenus des agriculteurs.

Cependant, si la production d'igname a connu une croissance remarquable depuis quelques décennies, cet accroissement s'explique pour plus des trois quarts par l'augmentation des surfaces. La conséquence est donc le déboisement de milliers d'hectares de formations végétales chaque année. En effet, l'igname étant cultivée en tête de succession culturale, elle est associée aux défriches de jachères de longue durée et il en résulte la disparition d'espaces forestiers et à terme, une dégradation du patrimoine forestier et des sols (Adifon et al., 2015 ; FAO, 2017).

Face à cet état de chose, le développement de nouvelles technologies de production d'igname qui concilient la gestion durable des terres, la préservation de la biodiversité et une agriculture résiliente aux dérèglements climatiques est un enjeu majeur. La présente synthèse bibliographique vise à faire l'état des lieux des travaux de recherche ayant porté sur les ignames en Afrique tropicale en général et au Bénin en particulier. À cet effet, une recherche documentaire a été menée dans différents centres de documentation universitaire, dans des institutions de recherche comme l'Institut national des recherches agricoles du Bénin (INRAB) et l'Institut international d'agriculture tropicale (IITA-Benin), et sur des sites de recherche en ligne; des entretiens avec des personnes ressources ont aussi été effectués. La sélection bibliographique est axée sur les questions méthodologiques et relatives à l'écologie, aux conditions climatiques, aux systèmes de culture et aux utilisations alimentaires des ignames. Les statistiques agricoles (production agricole, superficies des terres cultivables et cultivées et rendements) ont été collectées à la direction de la statistique agricole du ministère de l'Agriculture, de l'Élevage et de la Pêche du Bénin et dans les archives des services statistiques de la FAO (FAOSTAT).

\section{Botanique et domestication des ignames}

Les ignames, selon la classification faite par Coursey (1972) et rapportée par Scarcelli (2005) et Yolou et al. (2015), sont des Monocotylédones du genre Dioscorea. Elles font 


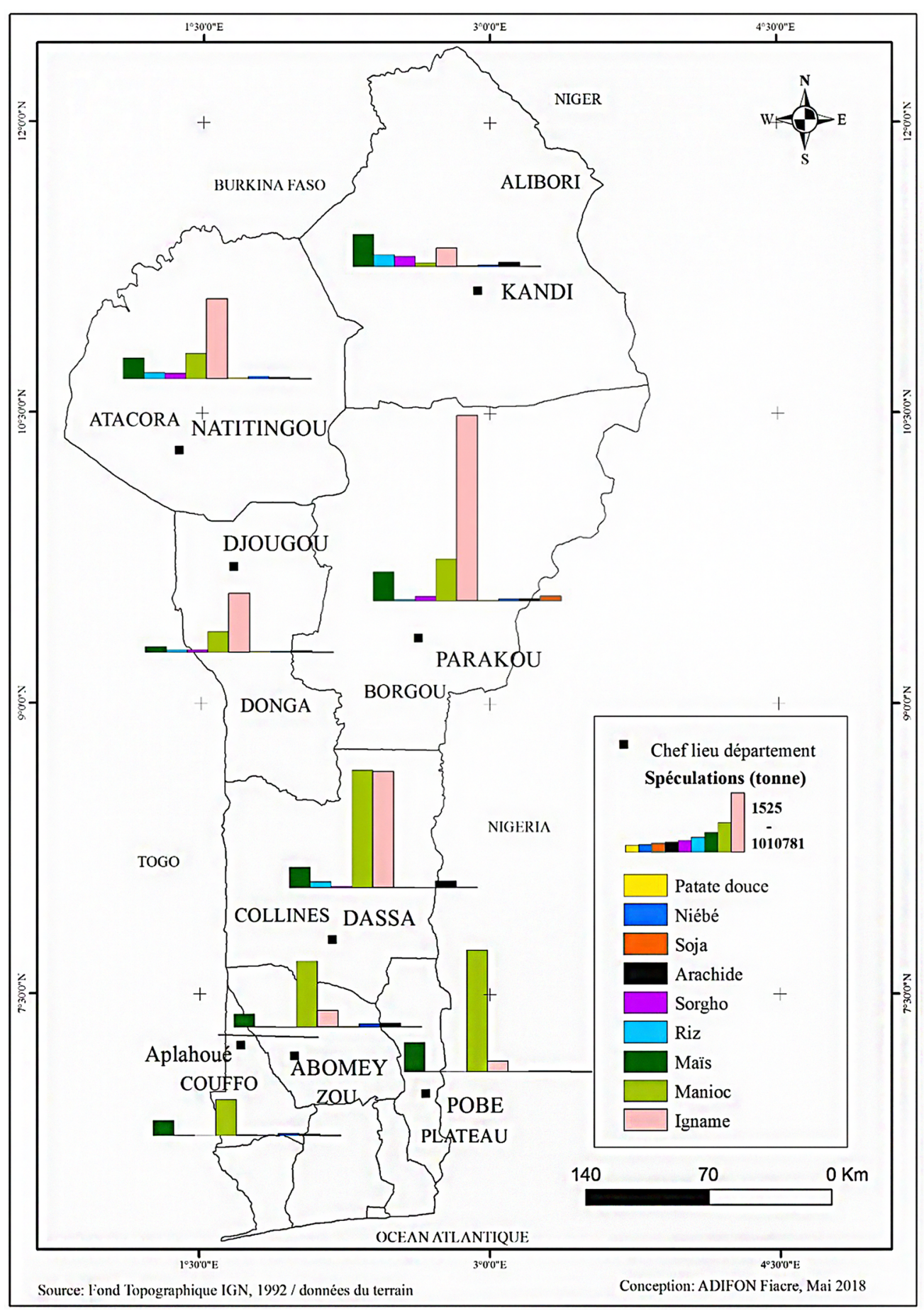

Fig. 1. Production en tonnes de l'igname et des cultures vivrières par département au Bénin. Source: DSA et MAEP (2017).

Fig. 1. Yam and other food crops productions (metric tons) in Benin departments.

partie de la famille des Dioscoréacées et de l'ordre des Dioscoréales. Une classification similaire a ensuite été faite par Degras (1986). Pour tous, les ignames appartiennent à l'embranchement des cormophytes et sont classées parmi les monocotylédones. Ce sont des végétaux lianescents et vivaces. Ce sont des plantes herbacées, grimpantes, à tige volubile, ou épineuse, de section cylindrique ou anguleuse qui comporte une partie vivace, souterraine ou non et une partie caduque, aérienne, plus mince. Leurs feuilles sont alternes ou opposées, glabres, cordiformes et à leur aisselle se développent souvent des bulbilles pouvant servir à la multiplication. Les tubercules qui se forment constituent la partie comestible de la plante. Ils sont cylindriques, sphériques ou lobulés, de couleur brune (Photo 1). Leur chair est blanche, jaune ou rougeâtre ; leur poids varie et peut atteindre $10 \mathrm{~kg}$. 


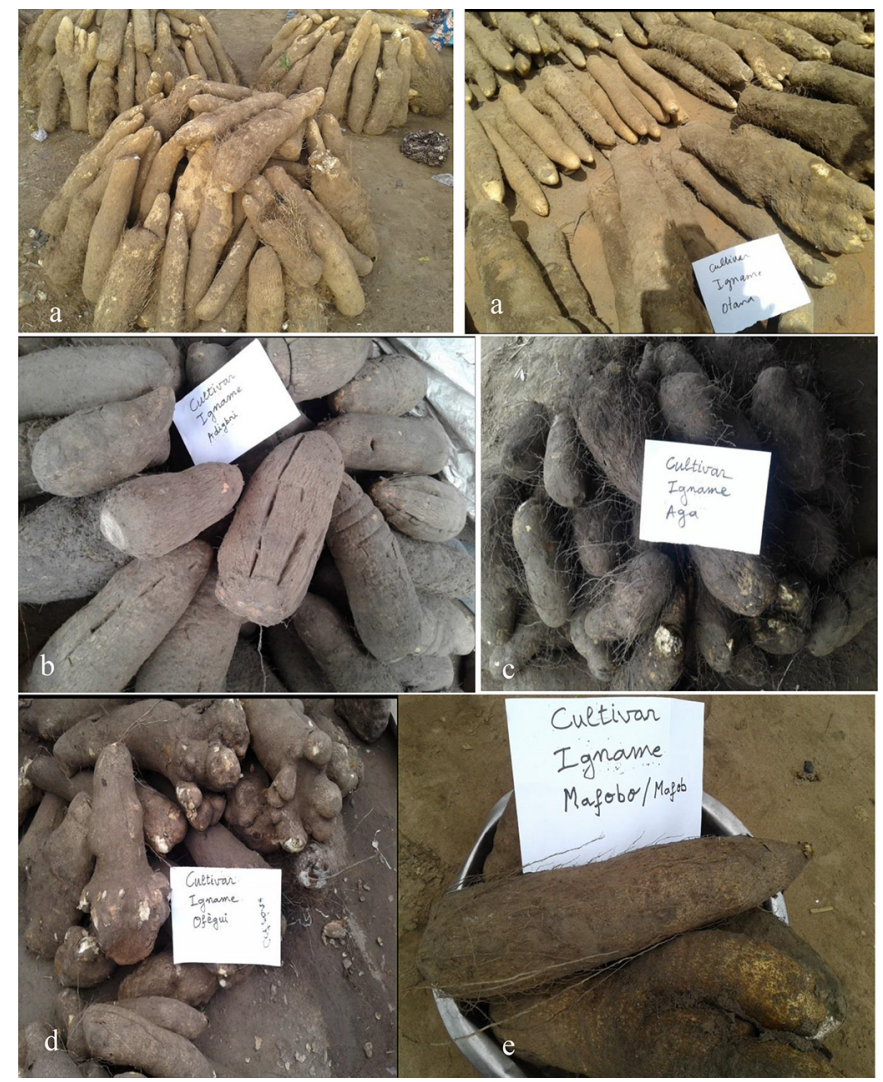

Photo 1. Tubercules d'igname ayant des formes différentes: (a) Kabletonan (en fon et nago, Centre du Bénin), Angba-Awobé (en baatonu, Nord-Est) et Otana (en otamari et wama, Nord-Ouest) $-D$. rotundata; (b) Adigbri «tubercule gros comme un tronc d'arbre» (en nago et idaâsha, Centre Bénin), Kpekpere (en baatonou, NordEst)-D. rotundata; (c) Aga (en idaâsha et ifè) et Aloungan (en fon) Sankounou en baatonu-D. alata; (d) Ofègui (D. rotundata); (e) Mafobo (en idaâsha, Centre Bénin), «ne doit pas être laissé à un fainéant»; variété nécessitant beaucoup d'entretien-D. rotundata.

Photo 1. Yam tubers with different shapes: (a) Kabletonan/AngbaAwobé/Otana (according to different local langages) - D. rotundata; (b) Adigbri/Kpekpere (D. rotundata); (c) Aga/Aloungan/Sankounou (D. alata); (d) Ofègui (D. rotundata); (e) Mafobo (D. rotundata).

Selon Zoundjihékpon (1993), Scarcelli (2005) et Cornet (2015), le genre Dioscorea comprend plus de 600 espèces dont quelques-unes seulement sont utilisées dans l'alimentation humaine. Il s'agit notamment de D. alata, D. dumetorum, D. bulbifera, D. rotundata, D.cayenensis et D. esculenta (Bricas et al., 1997; Maliki, 2013; Cornet, 2015).

Pour Scarcelli (2005), les variétés les plus importantes et les plus largement cultivées au Bénin sont celles du complexe $D$ rotundata-cayenensis. Il a souligné que les cultivars d'igname ouest-africaine ont été pour l'essentiel domestiqués par les paysans à partir de souches sauvages existant dans les savanes et les forêts comme D.abyssinica, D. praehensilis, D. bulbifera, D. togoensis, D. dumetorum et D. burkiliana (Tab. 1).

Au Bénin, selon Dansi et al. (2000) et Nonkoudje (2008), les principales espèces du genre Dioscorea cultivées sont:
- Dioscorea rotundata avec plus de 71 accessions à cycle précoce et 94 accessions à cycle tardif;

- Dioscorea alata avec 51 accessions;

- D. cayenensis (igname jaune) avec 2 accessions;

- D. dumetorum avec 2 accessions;

- D. bulbifera avec 1 accession.

Ainsi, on peut estimer à plusieurs centaines, les accessions des Dioscorea cultivées au Bénin. Vernier et Dansi (2006) estiment à 313 , regroupés en 26 morphotypes, les cultivars d'igname cultivés au Bénin. Ces différents cultivars se regroupent en deux grands types: les variétés à maturation précoce, généralement récoltées deux fois par an (variétés précoces) et les variétés tardives, récoltées une fois annuellement (Vernier et Dansi, 2006). Les facteurs déterminant le choix des variétés par les producteurs sont, entre autres : la qualité culinaire des tubercules, la productivité, la qualité des cossettes, la précocité de tubérisation, la valeur commerciale, la conservation, la facilité de culture, le niveau de multiplication, le rôle dans l'alimentation et les besoins pour les cérémonies rituelles. Les accessions Laboko, Gangni, Gnidou Kpouna, Morokorou Angba-Awobé sont assez cultivées au sein des Dioscorea rotundata à cycle précoce, tandis que Kokoro ou Yasounou et Gnalabou/Gnananb/Gnalbo et Baniouré sont préférées parmi les Dioscorea rotundata à cycle tardif.

Les critères utilisés dans la dénomination des ignames par les différents groupes ethniques du Bénin vont de la morphologie du tubercule ( Adigbirin»=«tubercule gros comme un tronc d'arbre») à ses qualités culinaires (« Kpakara » en bariba $=$ «qui soulève le bol », foutou - pâte - très tendre qui colle aux assiettes) en passant par ses caractéristiques agronomiques ( Aloungan »= « chef de la saison sèche» en mahi), ses conditions de culture ( $«$ Mafobo $»=«$ ne doit pas être laissé à un fainéant», variété nécessitant beaucoup d'entretien), sa valeur marchande («Wokourou » en bariba) ou même ses vertus pharmacologiques («Porchehbim» $=$ «seins de la femme», variété galactogène).

L'IITA, dans le souci de mettre à la disposition des producteurs des semences d'igname de qualité et de contribuer à la sécurité alimentaire, a introduit des variétés d'igname à haut rendement pouvant donner jusqu'à 25 tonnes de tubercules. Il s'agit des variétés TDr 131, TDr 205, TDr 89/02665, TDr 747, et TDR 179. Mais les taux d'adoption de ces variétés introduites par la recherche sont faibles (environ $36 \%$ ). Leur faible aptitude à faire de la bonne igname pilée, leur pourriture précoce, les attaques parasitaires élevées auxquelles elles sont sujettes, ainsi que leur forte teneur en eau, sont les principales contraintes à leur adoption (Maliki et al., 2012). La qualité organoleptique et le rendement constituent les critères les plus importants pour l'acceptation et l'adoption d'une nouvelle variété d'igname par les producteurs. La variété Florido (D. alata) a également été introduite au Bénin sous le nom d'Abidjandepuis des décennies. Cette variété sélectionnée à Porto Rico a été introduite en Côte d'Ivoire au début des années 1970 d'où elle s'est diffusée ensuite dans les pays voisins. Comme la majorité des D. alata, c'est une variété à une seule récolte qui produit des tubercules de formes arrondies (Doumbia et al., 2004 ; Cornet, 2015). 
Tableau 1. Origines et caractéristiques de quelques espèces d'igname.

Table 1. Origin and carateristics of some yam species.

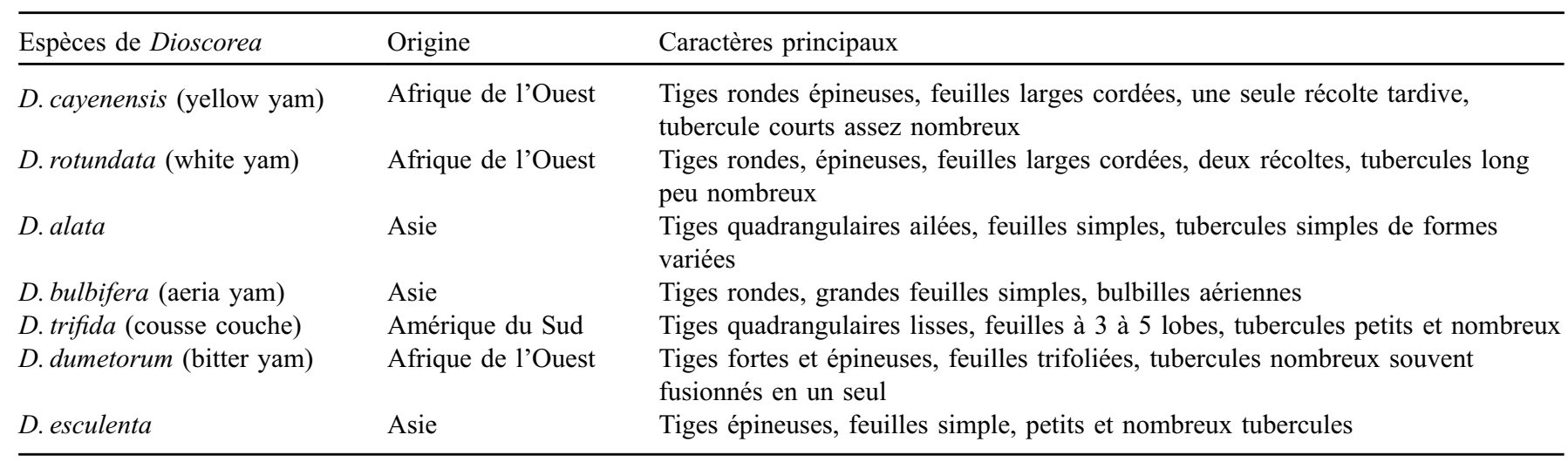

Source : CIRAD et GRET (2002)

La pratique «d'ennoblissement» (Dumont et al., 2005) permet également aux producteurs de domestiquer des ignames sauvages et de disposer des semenceaux (tubercules ou fragments de tubercule). Les agriculteurs collectent alors dans la savane ou la forêt des ignames sauvages aux tubercules filiformes, qu'ils replantent dans leurs champs. Après plusieurs années de culture, les plantes qui développent un tubercule de morphologie proche des variétés cultivées sont choisies par les cultivateurs pour être multipliées (Chaïr et al., 2010).

\section{3 Écologie de l'igname}

L'igname est un taxon d'espèces essentiellement tropicales qui nécessitent des températures élevées. La germination est optimale entre 25 et $30^{\circ} \mathrm{C}$, alors que des températures inférieures à $15^{\circ} \mathrm{C}$ ou supérieures à $35^{\circ} \mathrm{C}$ retardent la germination. À l'exception de Dioscorea japonica thunb, D. opposita, D. opposita et D. communis, la croissance est fortement ralentie en dessous de $20^{\circ} \mathrm{C}$ et augmente entre 25 et $30^{\circ} \mathrm{C}$. La photopériode semble influencer la croissance des tubercules: les jours courts, autour de 12 heures, caractéristiques des zones tropicales productrices d'igname, favorisent la tubérisation (Cornet, 2015). À l'opposé, les jours de plus de 12 heures semblent favoriser le développement de la partie aérienne. Selon Pouzet (1985), la floraison est aussi influencée par la photopériode. Ce constat de l'effet de la photopériode sur la croissance et le développement des ignames fait par Pouzet (1985) a été confirmé par différents auteurs dont Shiwachi et al. (2002), Vaillant et al. (2005) ainsi que Marcos et al. (2009). Le développement des tubercules de l'igname correspond également à une adaptation aux saisons sèches marquées. Durant la saison de culture, l'igname a donc besoin d'une importante quantité d'eau (Cornet, 2005). La culture se pratique avec succès dans des zones où la pluviométrie varie entre 1000 et $1800 \mathrm{~mm}$ (Degras, 1986). Cependant, certaines ignames sont cultivées dans des climats où la pluviométrie dépasse $3000 \mathrm{~mm}$ et, à l'opposé, il est possible de cultiver l'igname avec une pluviométrie de seulement $600 \mathrm{~mm}$, mais le rendement net reste faible et il n'est pas possible de réaliser deux récoltes (Cornet, 2005). Selon l'IITA (1994) et Cornet (2005), la bonne répartition des précipitations au cours du cycle est souvent plus importante pour la culture d'igname que leur volume total. Selon ces auteurs, la disponibilité en eau serait cruciale entre la quatorzième et la vingtième semaine de végétation. Au Bénin, les premières pluies qui suivent la période de plantation de l'igname, c'est-à-dire de janvier à avril pour les zones Centre et Nord-Est et janvier à mai pour la zone Nord-Ouest, déterminent significativement le rendement de l'igname. Cependant, une pluie qui survient en janvier affecte négativement le rendement des ignames quelle que soit la zone. En cours de cycle, l'igname peut tolérer de courtes périodes de stress hydrique, avec de grandes différences variétales (D.cayenensis, variété précoce, est réputé très exigeant en eau). Cette tolérance s'accompagne presque toujours d'une réduction du rendement; elle vient en grande partie des réserves disponibles dans le semenceau. La forte proportion d'eau dans le semenceau rend sa germination relativement indépendante du statut hydrique du sol. Mais une fois cette réserve épuisée, la sensibilité aux épisodes secs augmente (Metri et Carvallo, 1998).

Toutefois, les besoins hydriques réels des ignames sont loin d'être bien connus. En effet, contrairement à d'autres plantes à racines et tubercules comme la pomme de terre, le manioc ou la patate douce, dont les coefficients culturaux sont connus pour les différents stades de croissances, ceux de l'igname restent peu connus.

En ce qui concerne les conditions édaphiques, l'igname est tolérante à une large gamme de sols mais préfère des sols à texture limono-sableuse ou sablo limoneuse, ayant une porosité comprise entre 46 et $60 \%$, une conductivité hydraulique de $15 \mathrm{~cm} / \mathrm{h}$, une densité apparente du sol comprise entre 1,1 et $1,6 \mathrm{~g} \cdot \mathrm{cm}^{-3}$ et surtout un sol léger, profond $(>0,6 \mathrm{~m})$ et bien drainé (Cornet, 2005).

L'igname est aussi exigeante sur le plan de la qualité chimique et biologique du sol, qui doit être riche en matière organique, en azote, en potasse, en magnésium et en calcium, sans oublier le $\mathrm{pH}$ du sol qui doit être compris entre 5 et 7 (Degras, 1993). Le développement des tubercules d'igname requiert en effet des sols meubles, légers et riches en matière organique, surtout pour la variété locale Laboko qui est une variété précoce très appréciée des producteurs et des consommateurs au Bénin (Oshunsanya et Akinrinola, 2013; Adifon et al., 2019). 


\section{Systèmes de culture}

Les ignames occupent la tête de la rotation, même si l'introduction d'une seconde culture d'igname dans la succession culturale est une opération de plus en plus fréquente (Bricas et al., 1997 ; Baco et al., 2007; Gibigaye, 2013). La production d'igname demeure globalement extensive et son augmentation se fait essentiellement par un changement d'occupation des terres par défriche-brûlis des forêts naturelles ou des savanes arborées (Cornet, 2005 ; Baco et al., 2007 ; Dumont et al., 2010). Les champs d'igname sont alors installés après le défrichement de jachères relativement longues. Cette période varie selon les auteurs et selon l'époque des recherches: 10 à 15 ans d'après Okry (2000) et Houemassou Bossa (2001), mais 25 à 30 ans selon Pieri (1989). Les paysans privilégient des sols caractérisés par la présence d'une végétation dense (Houemassou Bossa, 2001 ; Baco et al., 2007). Dans les systèmes de culture pratiqués en Afrique tropicale, l'igname est cultivée en culture pure ou en association. Les cultures associées à l'igname sont principalement: le maïs, le manioc, le sorgho, le gombo et les cucurbitacées. Souvent, les champs d'igname comprennent également de nombreuses espèces et cultivars différents plantés en association.

Le niveau de production varie d'une zone de production à l'autre et est fonction de la variété utilisée (précoce, intermédiaire ou tardive), du système de culture (rotation ou association) et du type de terres exploitées : terres de défriche, de jachère de longue durée, de jachère de courte durée; au Bénin, les terres de bas-fond ou de lits de cours d'eau sont aussi de plus en plus utilisées dans les départements des Collines (Centre) et de l'Atacora (Nord-Ouest).

La sénescence marquée par le dessèchement des feuilles indique la fin du cycle de végétation et la maturité des tubercules pour la récolte. Le cycle végétatif est de 7 à 9 mois, mais les travaux nécessaires à la production d'igname s'étalent sur 8 à 12 mois (Cornet, 2015). En ce qui concerne les pratiques de stockage et de conservation, elles varient selon l'environnement. Le système traditionnel le plus important est l'utilisation des hangars ombragés. Toutefois, les tubercules peuvent être conservés au champ dans les buttes en attendant leur récolte. Il est à noter que toutes ces méthodes présentent des limites et ne permettent pas une bonne conservation post-récolte des tubercules. Cependant, les pertes peuvent être réduites en transformant l'igname en cossettes séchées (Photo 2), qui renferment moins d'eau que le tubercule frais.

\section{Pratiques culturales}

Au-delà des conditions climatiques et édaphiques, les pratiques culturales ont également un effet sur la productivité des ignames. Au nombre de ces pratiques qui peuvent influencer la production des ignames, il y a, entre autres, le travail du sol, le matériel de plantation, le tuteurage, la fertilisation, l'entretien...

\subsection{Travail du sol}

La confection de buttes comme lit de semis reste, en Afrique de l'Ouest, le principal mode de travail du sol pour la

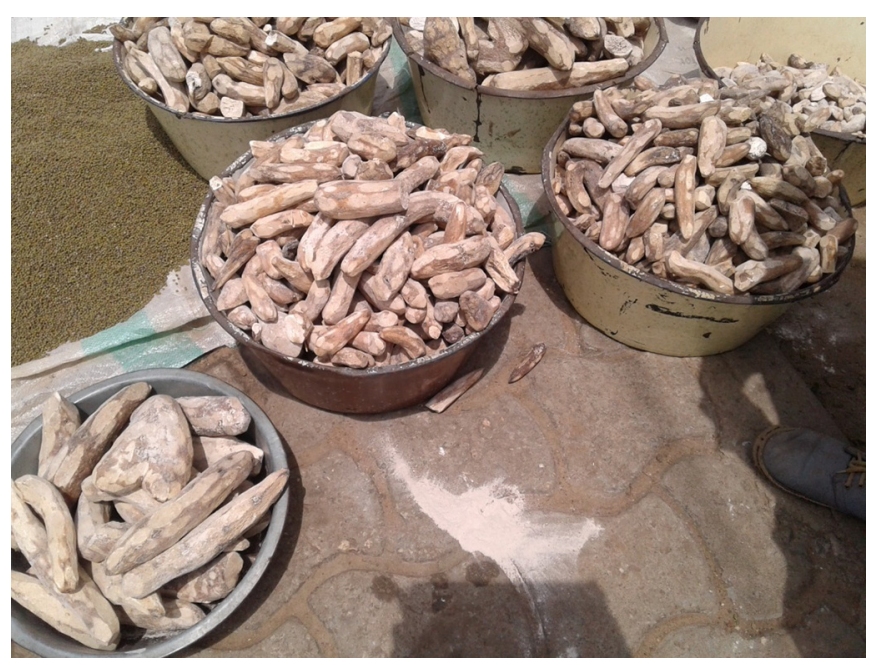

Photo 2. L'igname transformée en cossettes séchées.

Photo 2. Yam processed in dry chips.

plantation des ignames. Cette opération permet en effet de diminuer l'hétérogénéité du milieu en déstructurant le sol et en mélangeant ses différents horizons, ce qui contribue à atténuer l'inégalité entre plantes voisines pour l'accès aux éléments nutritifs, d'une part, et l'inégalité en termes de taux de croissance, de stade de développement ou de rendement, d'autre part (Cornet, 2015).

La hauteur des buttes d'igname varie selon les agriculteurs et est fonction de la topographie du champ et des cultivars. Selon Adifon et al. (2019), les producteurs d'igname de la zone Centre $(47,1 \%)$ et du Nord-Ouest $(26,7 \%)$ du Bénin, qui cultivent désormais l'igname dans des bas-fonds, dans les plaines inondables et dans le lit des cours d'eau, confectionnent des grosses buttes d'un mètre de hauteur ou parfois plus afin de mettre les tubercules à l'abri de l'hydromorphie dans ces zones basses. Les variétés produisant des tubercules longs et gros, comme Boki, Guiéna, Guirissa, Morokorou, Laboko, Noualaye, Oroutanai, Piédjè, Soagona, Soussouka, Terkokonou et Wossou, nécessitent des buttes de grande taille qui dépassent le mètre de hauteur (Adifon et al., 2019). Après plantation des semenceaux, les buttes d'igname sont très souvent protégées par un «chapeau » fabriqué avec des chaumes de poacées ou des débris végétaux trouvés sur place. Le chapeau permet de retenir l'humidité et de limiter l'élévation de la température à l'intérieur de la butte durant la saison sèche (Onwueme, 1976). Les densités de plantation, selon Nonkoudje (2008), sont fonction des objectifs, des variétés et des conditions pédoclimatiques. Ainsi, la production de gros tubercules de poids unitaire supérieur à $5 \mathrm{~kg}$ demande une faible densité de plantation de l'ordre de 3000 à 4000 pieds par hectare. Celle des tubercules moyens ( 1 à $2 \mathrm{~kg}$ ), plus recherchés en production commerciale, est obtenue avec des densités plus fortes fluctuant entre $4444(1,5 \times 1,5 \mathrm{~m})$ et 10000 pieds/ha $(1 \times 1 \mathrm{~m})$.

\subsection{Plantation et matériel végétal}

Dans la majorité des cas, l'igname est reproduite de manière végétative : des tubercules entiers ou des fragments de 
tubercules (semenceaux) issus de la récolte précédente sont plantés pour engendrer une nouvelle plante qui fournira la récolte suivante. Chez les variétés précoces de Dioscorea rotundata, les gros tubercules de première récolte sont réservés à la consommation, tandis que les tubercules de seconde récolte, plus petits, sont utilisés entiers comme semenceaux. Cependant, les secondes récoltes peuvent être insuffisantes, ce qui contraint les agriculteurs à utiliser comme semenceaux des fragments de tubercules de première récolte. Les variétés tardives ne procurent qu'une seule récolte. Si elle est suffisamment fournie en tubercules, les plus petits sont utilisés entiers comme semenceaux. À défaut, on découpe certains tubercules comme matériel de plantation. Dans ce dernier cas, le temps qui s'écoule entre cette découpe et la plantation peut varier d'un à quelques jours, selon la variété. La disponibilité en semenceaux est un important facteur limitant la production. Par conséquent, en période difficile, les paysans peuvent être contraints d'abandonner des milliers de buttes faute de semence. Contrairement au marché du tubercule de consommation qui se développe, celui des semenceaux tarde à s'organiser, fragilisant la filière tout entière.

Selon Ferguson (1973), Ferguson et al. (1980) et Cornet (2015), le tubercule mère semble exercer un contrôle précoce sur le développement de la plante. Ainsi, plus le tubercule mère est petit, plus vite la plante passe à l'autotrophie (avec des taux d'assimilation net plus élevés que pour les gros semenceaux). Ce passage à l'autotrophie détermine en quelque sorte la date à laquelle la plante devient sensible aux facteurs exogènes. En outre, les morceaux issus de la tête du tubercule germent également plus rapidement et permettent un gain de rendement. Selon Cornet (2015), le matériel de plantation utilisé (taille et qualité du semenceaux) peut ainsi introduire une forte variabilité initiale entre individus pour la croissance, la tubérisation, et finalement le rendement.

Au Bénin, la plantation a normalement lieu en décembre ou en janvier (Maliki, 2013). Des variétés telles que Laboko, Kpouna, Ankploman, Ofegui et Soagoné doivent être plantées dès le début du mois de décembre. Ces variétés sont parmi les premières à arriver sur les marchés, dès les mois de juilletaoût; elles doivent être consommées rapidement en raison de leur courte période de dormance. À l'inverse, certaines variétés locales sensibles à la chaleur, telles que Kodjewé, Gnananbo, Agatou, Baniouré, Kpakouvè ou Aloungan doivent être plantées profondément et tardivement vers la fin du mois de février, de manière à éviter la pourriture dans les buttes. La date de plantation varie fortement en fonction du début de la saison des pluies, mais aussi de la variété. Afin de conserver le semenceau jusqu'à la plantation, l'agriculteur a recours parfois à un égermage, technique qui consiste à casser la tige germée en cours de stockage. Il est important de noter que le moment de la journée le plus favorable pour la plantation est le matin de $6 \mathrm{~h} 30$ à 11 heures (Cornet, 2015).

Dans les trois quarts des cas, les semenceaux sont introduits latéralement dans la butte, du côté du soleil couchant, mais ils peuvent également être plantés au sommet de la butte, lorsque celle-ci est coiffée. Il s'agit toujours de pratiques visant à diminuer l'effet des chocs thermiques durant la période de fortes chaleurs de décembre à avril. Les ignames sont généralement plantées en lignes et regroupées par variété. Un tiers des paysans tient compte de l'influence lunaire et plante en lune montante. Le taux de levée avoisine généralement $95 \%$ mais peut diminuer drastiquement en conditions exceptionnelles (retard des pluies, mauvais semenceaux). Les tiges surnuméraires, lorsqu'elles apparaissent, sont maintenues, car elles promettent une récolte accrue.

\subsection{Tuteurage}

Les plants d'ignames font le plus souvent l'objet d'un tuteurage. C'est une opération qui consiste à fixer un support solide à côté de la butte autour duquel s'enroule la tige de l'igname (Cornet, 2015). Cela permet d'exposer un grand nombre de feuilles à la lumière donc d'intensifier l'activité photosynthétique et par conséquent d'augmenter le rendement en tubercules. Ainsi, la pratique du tuteurage est très bénéfique à l'igname surtout pour les variétés de D. rotundata à double récolte. Pour ce faire, les arbres présents sont tués sur pied pour servir de tuteur. En absence d'arbre à tuer sur la parcelle, des tuteurs sont amenés sur le champ. Les tiges des céréales, de la culture précédente, ou de la culture associée servent également de tuteurs. De nos jours, le tuteurage est limité en raison du coût de son installation (Adifon et al., 2019).

\subsection{Pratiques de fertilisation et d'irrigation}

De nombreux travaux de recherche relatifs à l'utilisation des fumures minérales et organiques, à l'agroforesterie, aux plantes de couverture et aux rotations culturales ont été réalisés ces dernières années au Bénin, en Afrique de l'Ouest et dans les régions tropicales. Ainsi, des essais de fertilisation minérale sur la croissance et l'élaboration du rendement des variétés d'igname de Dioscorea alata, de même que la fertilisation organique et minérale sur les variétés du complexe Dioscorea cayenensis-rotundata, ont été menés par Dumont et al. (1997), Strivastava et Gaiser (2008), Ettien et al. (2009), Aziadekey et al. (2014) et Cornet (2015). L'intérêt des légumineuses herbacées et de l'agroforesterie pour une production durable d'igname en Afrique de l'Ouest a fait également objet d'études ces dernières décennies (Kouame, 2003; Maliki et al., 2012). Il ressort globalement de ces études que l'igname répond positivement aux fumures azotée, potassique et organique. En revanche, les effets du phosphore sur le rendement des ignames sont faibles et mitigés. Concernant les doses, il est difficile de déterminer un optimum car, en plus des différences spécifiques et variétales, les études ont montré que les effets des éléments minéraux tels que $\mathrm{N}, \mathrm{P}$ et $\mathrm{K}$ varient en fonction des conditions écologiques et pédologiques, des précédents culturaux, des conditions d'application et des méthodes culturales. Les dates d'application des éléments minéraux dépendent du type d'engrais, de la variété et du sol. Un apport fractionné de l'azote est fortement recommandé. Une seconde application doit être faite 7 à 11 semaines après la première (faite à la plantation), en fonction de la durée du cycle de la variété. Toutefois, selon N'Goran et al. (2007), la fertilisation chimique peut avoir un effet négatif sur la conservation des tubercules d'igname, surtout chez $D$. cayenensis du fait d'une accumulation importante d'eau dans les tubercules.

\subsection{Entretien}

À la pratique du tuteurage qui a un effet bénéfique sur les rendements des ignames, il faut ajouter l'entretien des champs 
qui joue un rôle déterminant. En effet, l'igname est très sensible à la compétition avec les plantes adventices et l'absence de désherbage peut engendrer des baisses de rendement de l'ordre de 69 à $91 \%$ (Moody et Ezumah, 1974). Le développement de l'igname est lent et les densités de plantation pratiquées faibles. En pratique, cela se traduit par un nombre élevé de sarclages en cours de culture (de 2 à 6). À cause de son système racinaire superficiel, le sarclage de l'igname se révèle délicat: il est parfois nécessaire de «remonter» la butte afin de recouvrir de terre les racines mises à nu après le sarclage ou lors de fortes pluies. La gestion des adventices se fait pour beaucoup par des sarclages manuels. Ces sarclages répétés comptent souvent pour plus de $30 \%$ de la main-d'œuvre nécessaire à la production d'igname. Selon Adifon et al. (2019), de plus en plus d'agriculteurs, notamment de la zone Nord-Est du Bénin, ont également recours aux herbicides.

Enfin, le type de cultivar, la densité de plantation, la date de plantation, les adventices, les maladies et ravageurs, sans occulter l'histoire des parcelles et les pratiques paysannes de gestion du sol, ont également un impact sur les rendements des ignames. Face à la diversité spécifique et variétale, il faudrait mieux connaître les besoins physiques, biologiques, chimiques de chaque cultivar.

\subsection{Transformation et consommation des ignames}

Au Bénin, l'igname est produite comme culture vivrière dans huit départements sur les 12 que compte le pays. Dans les régions du centre et du nord du pays, l'igname représente un aliment de base des populations et peut se consommer deux à trois fois par jour au cours de certaines périodes de l'année, sous différentes formes (Baco et al., 2007; Maliki, 2013).

La consommation sous forme pilée, appelée «tchokourou » en bariba et «agou » en fon, et plus connue dans la sousrégion d'Afrique de l'Ouest sous le nom de «foutou», est la forme la plus appréciée des populations du centre et du nord du Bénin. La consommation des ignames prend aussi de l'ampleur dans les villes du sud telles que Cotonou, Abomey-Calavi, Bohicon, etc. La variété d'igname Laboko ou Kpouna (D. rotundata), à cycle précoce (Photo 3), est la plus appréciée des consommateurs du Bénin pour la confection de l'igname pilée. Les autres formes de consommation à partir des tubercules frais sont: la purée d'igname ou «pèrèkou» en bariba, l'igname frite surtout commercialisée avec le beignet de niébé. Le télibowo (en fon), ou amala (en yoruba) est une pâte de texture ferme et élastique, différente de celle de l'igname pilée, obtenue à partir de la farine de cosettes d'igname (Hounhouigan et al., 2003). À partir de cette farine, on prépare également le Wassa-wassa qui est un produit roulé de type couscous.

Le procédé technologique de fabrication des cossettes consiste, selon Okaka et al. (1991), à éplucher, à blanchir, à sécher les tubercules et à les concasser avant de les moudre. Le séchage et la pré-cuisson sont les étapes critiques du processus de transformation (Hounhouigan et Akissoe, 1997). Le séchage a lieu durant la période de l'harmattan, bénéficiant ainsi des avantages de l'air sec apporté entre novembre et mars par ce vent venant du Sahara et du Sahel. Les cossettes les plus recherchées sont celles fabriquées à partir des variétés tardives

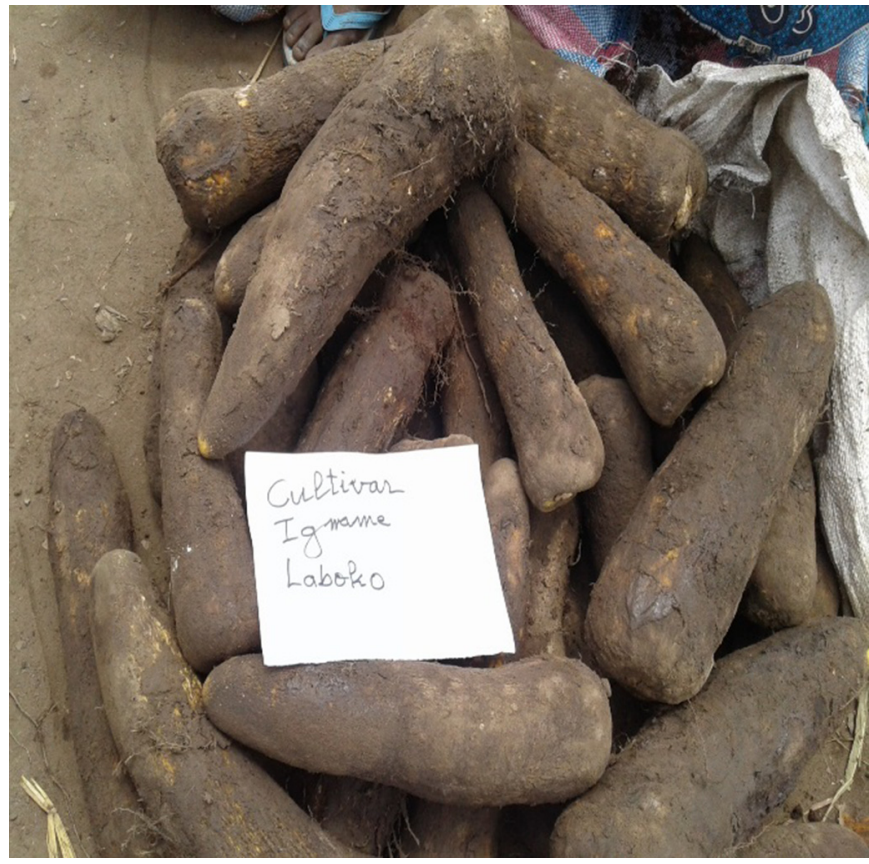

Photo 3. Cultivar d'igname Laboko à cycle précoce (Dioscorea rotundata).

Photo 3. Laboko, short-cycle yam cultivar (Dioscorea rotundata).

de D. rotundata, notamment Kokoro ou Yasounou (Hounhouigan et Akissoe, 1997 ; Vernier et al., 1999). Ces variétés sont récoltées de décembre à février. À l'opposé des D. rotundata, les cultivars de D. alata sont moins appréciés pour la production de cossettes. Cependant, les travaux de Vernier et al. (1999) ont montré que la variété Florido (D. alata) permettrait de produire des cossettes de qualité acceptable. Florido, connue pour ses qualités agronomiques et organoleptiques, est souvent plus appréciée que les D. alata locales; ce qui explique le succès de son introduction en Côte d'Ivoire à partir des années 1970 (Rodriguez, 1983). Sa diffusion s'est faite spontanément dans les pays voisins, tels que le Ghana, sous le nom de «Matches» (car on peut utiliser comme semenceaux des fragments de tubercules de la taille d'une boîte d'allumettes), et plus tard au Bénin dans les années 1990 sous le nom de «Abidjan».

\section{Contraintes et perspectives pour une production durable des ignames en Afrique de l'Ouest et au Bénin}

Au cours des dernières décennies, la production d'igname en Afrique tropicale a plus que triplé, faisant de l'igname la deuxième production alimentaire de la sous-région d'Afrique de l'Ouest. Toutefois, l'accroissement régulier de la production d'igname est beaucoup plus lié à l'augmentation des superficies qu'à celle des rendements. Des milliers d'hectares de forêts et savanes sont dès lors défrichés chaque année et des pays producteurs d'igname comme le Bénin, qui dispose de maigres ressources forestières, sont condamnés à la dégradation effrénée de leurs ressources forestières avec pour conséquence une menace pour la biodiversité et la libération 
du carbone séquestré dans les formations végétales et les sols, contribuant ainsi au réchauffement global de la terre (Yabi et Afouda, 2012).

De plus, dans les zones où les jachères de longue durée ne sont plus réalisables à cause de la pression foncière, la production d'igname a fortement diminué, ou a évolué vers des variétés plus rustiques et de moins bonne aptitude à l'igname pilée, et peut aller jusqu'à l'abandon de la culture. Cette production s'est aussi fortement insérée dans l'économie marchande et est passée d'un statut de culture vivrière à celui de culture de rente, en partie exportée vers les pays limitrophes. De ce fait, l'abandon ou la régression de sa production dans certaines régions du Bénin pose des problèmes d'insécurité alimentaire et de perte de revenus pour les agriculteurs.

Face à ces contraintes qui contribuent à la régression des superficies allouées à la culture des ignames dans les régions où les terres riches de forêts et savanes se font rares, l'Institut national des recherches agricoles du Bénin (INRAB) a proposé de nouvelles techniques à base de dispositifs agro-forestiers, pour promouvoir la sédentarisation de la culture des ignames et la sauvegarde des forêts (Maliki, 2013). Dans le cadre de la recherche-développement dans le centre du Bénin, ont ainsi été testées des jachères améliorées et l'utilisation:

- de légumineuses arbustives et herbacées dont Aeschynomene histrix, Mucuna pruriens var utilis, et Gliricidia sepium, comme précédents culturaux à la culture de l'igname ;

- d'une rotation avec une association Mucuna pruriens var utilis/maïs $+100 \mathrm{~kg} / \mathrm{ha}$ d'engrais NPK $14-23-14+50 \mathrm{~kg} /$ ha d'urée appliqués à l'igname ;

- d'une rotation avec Aeschynomene histrix/maïs $+100 \mathrm{~kg} /$ ha d'engrais NPK 14-23-14 + 50 kg/ha urée appliqués à l'igname ;

- d'une rotation jachère à Andropogon gayanus-igname (Maliki, 2013).

\section{Conclusion}

De nombreux acquis de la recherche sont donc disponibles, que ce soit au Bénin ou ailleurs en Afrique de l'Ouest. Mais dans le contexte des mutations environnementales (changements climatiques, appauvrissement et accélération de la dégradation des terres) et sociales (accroissement rapide de la population, des besoins et modes alimentaires), les conditions requises pour une véritable optimisation de la production des ignames et la durabilité des pratiques culturales innovantes sont encore mal connues et méritent d'être approfondies. Il est donc nécessaire, dans une approche visant une production d'igname plus durable, de continuer à développer de nouvelles technologies et de mieux caractériser les facteurs édaphiques, climatiques, agronomiques et socio-économiques, déterminants pour une amélioration des rendements, en tenant compte de l'importante variabilité des cultivars d'igname en Afrique de l'Ouest et de leurs qualités alimentaires.

\section{Références}

Adeniji O, Adebayo C, Ajayi, O. 2012. Analysis of marketing margin of yam in selected rural areas of Niger State, Nigeria. Basic
Research Journal of Agricultural Science and Review 1(3): 58-62. Available from http//www.basicresearchjournals.org.

Adifon F, Azontondé A, Houndantode J, Amadji G, Boko M. 2015. Évaluation des caractéristiques chimiques des sols sableux du littoral sous-système maraîcher au Sud-Bénin. Annales des sciences agronomiques 19(2): 53-68.

Adifon F, Yabi I, Balogoun I, Dossou J, Saïdou A. 2019. Caractérisation socio-économique des systèmes de culture à base d'igname dans trois zones agro-écologiques pour une gestion durable des terres au Bénin. European Scientific Journal 15(12): 211-232. DOI: 10.1944/esj.2019.v15n12p211.

Asiedu R, Sartie A. 2010. Crops that feed the World 1. Yams Yams for income and food security. Food Security 2(4): 305-315. DOI: 10.1007/s12571-010-0085-0.

Aziadekey M, Sogbedji M, Odah K, Amouzouvi K, Afanahin K. 2014. Effet de la fumure organo-minérale sur la production et les qualités organoleptiques de deux variétés d'ignames du complexe Dioscorea cayenensis-rotundata dans la région de Kara au Togo. European Scientific Journal 10(15): 178-191. DOI: 10.19044/ esj.2014.v10n15p\%25p.

Baco MN, Tostan S, Mongbo R, Biaou G, Lescure JP. 2007. Igname, plante alimentaire commerciale et culturelle au Nord Benin. Annales des sciences agronomiques du Bénin 9(2): 49-67. Disponible sur http://www.ajol.info.

Bricas N, Vernier P, Ategbo E, Hounhouigan JD, Mitchikpe E, Etoudo N'Kpenu K, et al. 1997. Le développement de la filière cossettes d'igname en Afrique de l'Ouest. Cahiers de la recherche développement 44(2): 100-114. Disponible sur http://cahiersrecherche-developpement.cirad.fr/.

Chaïr H, Cornet D, Deu M, Baco MN, Agbangla A, Duval MF, et al. 2010. Impact of farmer selection on yam genetic diversity. Conservation Genetics 11: 2255-2265.

CIRAD, GRET. 2002. Mémento de l'agronome. Paris : Ministère des Affaires Étrangères, 1691 p.

Cornet D. 2005. Étude du fonctionnement physiologique d'un couvert végétal d'igname (Dioscorea alata L.). Mémoire présenté pour l'obtention du diplôme d'étude approfondie en sciences agronomiques et ingénierie biologique, préalable au Doctorat. Disponible sur https://agritrop.cirad.fr/533539/1/ document_533539.pdf.

Cornet D. 2015 . Influence des premiers stades de croissance sur la variabilité du rendement parcellaire de deux espèces d'igname (Dioscorea spp.) cultivées en Afrique de l'Ouest. Thèse de Doctorat unique ès Sciences agronomiques et écologiques, Institut des Sciences et Industries du Vivant et de l'Environnement (AgroParisTech), 174 p.

Coursey D. 1972. The civilizations of the yam: Interrelationships of man and yams in Africa and the Indo-Pacific region. Archeol Phys Anthropol Oceania 7(3): 215-233.

Dansi A, Mignouna H, Zoundjihékpon J, Sangare A, Ahoussou N, Asiedu R. 2000. Identification of some Benin Republic's Guinea yam (Dioscorea cayenensis/Dioscorea rotundata complex) cultivars using randomly amplified polymorphic DNA. Genetic Resources and Crop Evolution 47: 619-625. DOI: 10.1023/ A:1026589702426.

Degras L. 1986. L'igname, plante à tubercule tropicale. In : Collection Techniques agricoles et productions tropicales. Paris (France) : Maisonneuve et Larose, 408 p.

Degras L. 1993. The Yam: A Tropical Root Crop. London: MacMillan Press, 408 p.

Doumbia S, Tshiunza M, Tollens E, Stessens J. 2004. Rapid spread of the Florido yam variety (Dioscorea alata) in Ivory Coast. Introduced for the wrong reasons and still a success. Outlook 
Agriculture 33(1): 49-54. Available from https://journals.sagepub. com.

DSA (Direction de la statistique agricole). 2017. Base de données sur l'évolution de la production d'igname de 1995-1996 à 2015-2016. Base Excel. Disponible sur http://benin.countrystat.org/home/fr/.

DSA et MAEP (Direction de la statistique agricole du ministère de l'Agriculture, de l'Élevage et de la Pêche). 2017. Évolution de production des principales cultures au Bénin. Disponible sur http:// benin.countrystat.org/home/fr/.

Dumont R, Letourmy P, Kouakou A. 1997. Influence de la fertilisation chimique sur l'aptitude de la conservation des ignames en Côte d'Ivoire. Cahiers Agricultures 6(2): 107-114.

Dumont R, Dansi AA, Vernier P, Zoundjihékpon J. 2005. Biodiversité et domestication des ignames en Afrique de l'Ouest. Pratiques traditionnelles conduisant à Dioscorea rotundata Poir. Coll. Repères. Montpellier (France) : CIRAD-IPGRI.

Dumont R, Zoundjihékpon J, Vernier P. 2010. Origine et diversité des ignames Dioscorea rotundata Poir. Domestication des ignames sauvages en Afrique. Cahiers Agricultures 19(4): 255-261. DOI: 10.1684/agr.2010.0411.

Ettien D, Koné B, Kaouadio K, Kouandi N, Yao-Kouamé A, Girardin O. 2009. Fertilisation minérale des ferralsols pour la production d'igname en zone de Savane Guinéenne de l'Afrique de l'Ouest: cas des variétés d'igname traditionnelle sur dystric ferralsols du Centre de la Côte d'Ivoire. J Appl Biosci 23: 1394-1402. Disponible sur http://www.m.elewa.org/JABS/2009/23/4.pdf.

FAO. 2017. La situation des forêts du monde. Les forêts au service du développement durable. Rome (Italie) : FAO. Disponible sur http:// www.fao.org/3/I9535FR/i9535fr.pdf.

FAOSTAT. 2019. Disponible sur http://www.fao.org/faostat/fr/\#data.

Ferguson TU. 1973. The effect of sett characteristics and spacing on growth, development and yield of yams (Dioscorea spp). PhD Thesis, University of the West Indies, St Augustine, Trinité et Tobago.

Ferguson TU, Haynes PH, Spence JA. 1980. Distribution of dry matter and mineral nutrients in tubers of two cultivars of Dioscorea alata L. Tropical Agriculture (Trinidad) 57: 61-67.

Gibigaye M. 2013. Effets environnementaux de la production de l'igname sur le système agroforestier dans la commune de Ouaké au Bénin. Int J Biol Chem Sci 7(3): 961-977. DOI: 10.4314/ijbcs. v7i3.7.

Houemassou Bossa J. 2001. Gestion de la diversité variétale au sein du complexe Dioscorea cayenensis-D. rotundata et la domestication de $D$. praehensilis : savoirs locaux et pratiques endogènes dans la sous-préfecture de Djidja. Thèse d'ingénieur, Université d'Abomey-Calavi, Bénin.

Hounhouigan J, Akissoe N. 1997. Diagnostic des systèmes techniques de transformation de l'igname en cossettes et en produits dérivés au Bénin. La valorisation de l'igname pour les marchés urbains. Rapport final. CIRAD-FSA-INCV-NRCRI.

Hounhouigan J, Kayode A, Bricas N, Nago C. 2003. Les caractéristiques culinaires des ignames recherchées en milieu urbain au Bénin. Annales des sciences agronomiques du Bénin 4 (2): 143-160. Disponible sur http://www.annales-fsa.bj.refer.org/ article.php3?.

IITA. 1994. Production des ignames: rôle actuel et perspectives d'avenir. Guide de recherche de 1'IITA n ${ }^{\circ} 46$. Ibadan, Nigéria: PMB 5320, 36 p.

Kouame J. 2003. Rôle de la jachère améliorée à légumineuses arbustives dans la stabilisation de la culture d'ignames en zone de forêts dégradées. Agron Afr 4: 147-152. Disponible sur https:// www.ajol.info/index.php/aga/article/viewFile/1725/623.

Maliki R. 2013. Gestion de la fertilité des sols pour une meilleure productivité dans les systèmes de culture à base d'igname au Bénin.
Thèse de Doctorat unique ès sciences agronomiques, Université d'Abomey-Calavi, 265 p.

Maliki R, Sinsin B, Floquet A. 2012. Evaluating yam-based cropping systems using herbaceous legumes in the savannah transitional agro-ecological zone of Benin. Journal of Sustainable Agriculture 36: 1-21. DOI: 10.1080/10440046.2011.646352.

Marcos J, Lacointe A, Tournebize R, Bonhomme R, Sierra J. 2009. Water yam (Dioscorea alata L.) development as affected by photoperiod and temperature: Experiment and modeling. Field Crops Research 111: 262-268. DOI: 10.1016/j.fcr.2009.01.002.

Metri J, Carvallo H. 1998. Coeficientes hidricos do inhame (Dioscorea cayenensis Lam.). Agro-Ciencia 14: 329-333.

Moody K, Ezumah HC. 1974. Weed control in major tropical root and tuber crops: A review. PANS 20(3): 292-299.

N'Goran K, Zohouri P, Yoro R, Kouakou MA, Assa A, Asiedu R. 2007. Revue bibliographique sur la gestion de la fertilité des sols cultives en igname en côte d'ivoire. Agronomie Africaine 19(3): 281-288. DOI: 10.4314/aga.v19i3.1725.

Nonkoudje P. 2008. Évaluation agronomiques des cultivars d'ignames en conservation au CRA Nord de 1997 à 2016. Rapport de fin de formation pour l'obtention de la Licence Professionnelle à l'École Polytechnique de 1'Université d'Abomey-Calavi, $91 \mathrm{p}$.

Okaka J, Okorie P, Ozo O. 1991. Quality evaluation of sun-dried yam chips. Tropical Science 30: 265-275.

Okry F. 2000. L'igname dans les systèmes de production agricoles de Bantè et la domestication de quelques-unes unes de ses formes sauvages: savoirs locaux et pratiques endogènes de culture et d'amélioration génétique. Thèse d'ingénieur agronome. FSA/ UAC.

Olufemi O, Olusegun R, Olayemi J, Johnson K. 2016. Effects of soil physical properties on soil loss due to manual yam harvesting under a sandy loam environment. International Soil and Water Conservation Research 4: 121-125. DOI: 10.1016/j. iswcr.2016.02.007.

Onwueme IC. 1976. Performance of yam (Dioscorea spp.) setts planted without water. Journal of Agricultural Science 87: 413415.

Onyeka T, Petro D, Ano G, Etienne S, Rubens S. 2006. Resistance in water yam (Dioscorea alata) cultivars in the French West Indies to anthracnose disease based on tissue culture-derived whole-plant assay. Plant Pathology 55(5): 671-678. Available from http:// www.sipav.org/main/jpp/index.php/jpp/index.

Oshunsanya S, Akinrinola T. 2013. Changes in soil physical properties under yam production on a degraded soil amended with organomineral fertilizers. African Journal of Agricultural Research 8(39): 4895-4901. DOI: 10.5897/AJAR2011.708.

Pieri C. 1989. Fertilité des terres de savanes. Paris: Ministère de la Coopération et du Développement, et CIRAD, $444 \mathrm{p}$.

Pouzet D. 1985. L'igname. Montpellier (France) : IRAT-CIRAD, 10 p.

Rodriguez H. 1983. Intérêt d'une variété d'igname portoricaine en Côte d'Ivoire: la Florido. Agronomie tropicale 38: 154-157.

Sanginga N, Mbabu A. 2015. Racines et tubercules (manioc, igname, pomme de terre et patate douce). Document de référence. Banque africaine de développement, 35 p. Disponible sur https://www. afdb.org/fileadmin/uploads/afdb/Documents/Events/DakA gri2015/Racines_et_Tubercules_Manioc_Igname_Pomme_ de_Terre_et_Papate_Douce_.pdf.

Scarcelli N. 2005. Structure et dynamique de la diversité d'une plante cultivée a multiplication végétative : le cas des ignames au Benin (Dioscorea sp.). Thèse de Doctorat en Ressources Phylogénétiques et Interactions Biologiques, Université Montpellier II Sciences et Techniques du Languedoc, 229 p. 
Shiwachi H, Ayankanmi T, Asiedu R. 2002. Effect of day length on the development of tubers in yam (Dioscorea spp.). Trop Sci 42: $162-170$.

Sodjinou E, Agli C, Adegbola P. 2009. Consommation et préférence des produits d'igname par les ménages urbains de Cotonou et de Porto-Novo, au Bénin. In: Nkamleu N, Annang D, Baco M. Securing levelihood through yams. Proceeding of a technical workshop on progress in yam research for developpement in west and central Africa held in Accra, Ghana, 11-13 September 2009.

Strivastava AK, Gaiser T. 2008. Biomass production and partitioning pattern of yam (Dioscorea rotundata). Agricultural Journal 3(5): 334-337. Available from http://researchgate.net/profile/Amit_Sri vastava33/publication/264740203_Biomass_production_and_Par titioning_pattern_of_Yam_.

Vaillant V, Bade P, Constant C. 2005. Photoperiod affects the growth and development of yam plantlets obtained by in vitro propagation. Biol Plant 49: 355-359. Available from https://link.springer.com/ article/10.1007/s10535-005-0007-8.

Vernier P, Dansi A. 2006. Participatory assessment of local yam cultivars (Dioscorea cayenensis and D. rotundata) in Benin. Plant
Genetic Resources Newsletter 147: 38-45. Available from http:// agritrop.cirad.fr/538487/1/ID538487.pdf.

Vernier P, Dossou R, Letourmy P. 1999. La fabrication des cossettes à partir d'igname Dioscorea alata: influence de la variété et du type de cossettes sur le séchage la conservation et les qualités organoleptiques. African Journal of Root and Tuber Crops 3: 62-67. Disponible sur http://publications.cirad.fr/une_notice.php? $\mathrm{dk}=475678$.

Yabi I, Afouda F. 2012. Extreme rainfall years in Benin (West Africa). Quaternary International 262(7): 39-43. DOI: 10.1016/j. quaint.2010.12.010.

Yolou M, Zoundjihékpon J, Assaba E, Anizehou I, Akoegninou A. 2015. La floraison des ignames africaines cultivées (D. cayenensis$D$. rotundata et $D$. dumetorum) dans les champs des producteurs du Centre-Bénin. Journal of Applied Biosciences 91: 8480-8492. DOI: 10.4314/jab.v91i1.1.

Zoundjihékpon J. 1993. Biologie de la reproduction et génétique des ignames cultivées de l'Afrique de l'ouest, Dioscorea cayenensis D. rotundata. Thèse de Doctorat d'Etat de l'Université Nationale de Côte d'Ivoire, 306 p.

Citation de l'article : Adifon FH, Yabi I, Vissoh P, Balogoun I, Dossou J, Saïdou A. 2019. Écologie, systèmes de culture et utilisations alimentaires des ignames en Afrique tropicale: synthèse bibliographique. Cah. Agric. 28: 22. 